\title{
Blechnaceae da Estação Ecológica do Panga, Uberlândia, Minas Gerais, Brasil
}

\author{
Adriana A. Arantes ${ }^{1,3}$, Jefferson Prado $^{2}$ e Marli A. Ranal ${ }^{3}$
}

Recebido: 11.10.2007; aceito: 26.06.2008

\begin{abstract}
Blechnaceae of the Ecological Station of Panga, Uberlândia, Minas Gerais State, Brazil). This paper provides the taxonomic treatment for the species of Blechnaceae of the Ecological Station of Panga. This Ecological Station covers an area of 409.5 hectares located about $30 \mathrm{~km}$ far from the city of Uberlândia, Minas Gerais State, Brazil. It is one of the few areas of the region with natural vegetation with different savannah physiognomies and forest formations. One genus and four species of Blechnaceae (Blechnum brasiliense Desv., B. lanceola Sw., B. occidentale L., and B. regnellianum (Kunze) C. Chr.) were found. Identification key, descriptions, illustrations of diagnostic characters of the species, geographical distribution, and comments are presented.
\end{abstract}

Key words: Blechnaceae, ferns, savannah

RESUMO - (Blechnaceae da Estação Ecológica do Panga, Uberlândia, Estado de Minas Gerais, Brasil). O presente trabalho apresenta o tratamento taxonômico das espécies de Blechnaceae da Estação Ecológica do Panga. Essa Estação Ecológica abrange 409,5 ha, situada a $30 \mathrm{~km}$ da cidade de Uberlândia, MG, Brasil. A área é considerada uma das poucas da região com formações de vegetação natural, incluindo diferentes fisionomias de Cerrado e formações florestais. Um gênero e quatro espécies de Blechnaceae (Blechnum brasiliense Desv., B. lanceola Sw., B. occidentale L. e B. regnellianum (Kunze) C. Chr.) foram encontradas. São apresentadas chave para as espécies, descrições, ilustrações dos caracteres diagnósticos, distribuição geográfica e comentários dos táxons.

Palavras-chave: Blechnaceae, cerrado, samambaias

\section{Introdução}

A riqueza florística de pteridófitas é elevada no bioma Cerrado (Mendonça et al. 1998), com altas taxas de endemismo em algumas regiões (Prado 1992) e relativamente poucos estudos florísticos (Prado 1992, 1997). Mendonça et al. (1998) citam a ocorrência de 282 táxons, pertencentes a 267 espécies, 51 gêneros e 19 famílias de pteridófitas para o Cerrado. Cerca de $76 \%$ das espécies ocorrem nas formações florestais do bioma, como matas de galeria, matas secas e cerradões, e apenas $37 \%$ e $30 \%$ nas formações savânicas e campestres, respectivamente.

A região do Triângulo Mineiro, onde está situada a área de estudo, é considerada uma das mais críticas em termos de conservação, por restarem poucos remanescentes deste bioma e poucas unidades de proteção integral (Drummond et al.2005). O presente trabalho é parte do levantamento florístico das samambaias da Estação Ecológica do Panga (E.E.P.), que vem sendo realizado pelo Instituto de Biologia da Universidade Federal de Uberlândia, desde 1986. A pteridoflora desta área está representada por 52 espécies, 15 famílias e 22 gêneros. Thelypteridaceae é a mais rica entre as samambaias, com 14 espécies e dois gêneros (Arantes et al. 2008, 2007a, b), seguida de Pteridaceae e Polypodiaceae, com quatro gêneros e sete espécies cada.

Este estudo traz o tratamento taxonômico para Blechnaceae da E.E.P., com chave de identificação, sinonímia, ilustrações, distribuição geográfica e comentários sobre as espécies.

\section{Material e métodos}

A Estação Ecológica do Panga (E.E.P.) abrange 409,5 ha e está situada a $30 \mathrm{~km}$ ao sul do centro da cidade de Uberlândia, MG, entre as coordenadas $19^{\circ} 09^{\prime} 20^{\prime \prime}-19^{\circ} 11^{\prime} 10^{\prime \prime} \mathrm{S}$ e $48^{\circ} 23^{\prime} 20^{\prime \prime}-48^{\circ} 24^{\prime} 35^{\prime \prime} \mathrm{W}$, a 740-840 m de altitude (Araújo et al. 2002). A área

1. Universidade Federal de Uberlândia, Instituto de Biologia, Caixa Postal 593, 38400-902 Uberlândia, MG, Brasil

2. Instituto de Botânica, Caixa Postal 3005, 01061-970 São Paulo, SP, Brasil

3. Autor para correspondência: adrianassisa@hotmail.com 
apresenta fisionomias comuns do bioma Cerrado como campestres (Campo Sujo, Campo Limpo Úmido), savânicas (Cerrado sentido restrito, Veredas) e florestais (Cerradão, Mata seca e Mata de galeria) (Ribeiro \& Walter 1998).

Os espécimes testemunhos foram coletados, herborizados e depositados nos Herbários HUFU e SP. O tratamento taxonômico é apresentado em ordem alfabética de espécies e segue o sistema de classificação de Smith et al. (2006).

As descrições foram elaboradas com base nos caracteres morfológicos dos espécimes coletados na área e, quando necessário, complementadas com material de áreas próximas. A terminologia morfológica adotada está de acordo com Lellinger (2002). As descrições da família e gêneros foram baseadas nos trabalhos de Moran (1995) e Smith et al. (2006). As abreviações dos nomes dos autores de táxons seguiram Pichi-Sermolli (1996).

\section{Resultados e Discussão}

Blechnaceae Newman, Hist. Brit. Ferns, ed. 2: 8. 1844.

Plantas terrestres, rupícolas ou raro epífitas, hemiepífitas ou trepadeiras. Rizoma horizontal, ereto ou escandente, ocasionalmente com hábito arborescente, freqüientemente formando estolões, com escamas não clatradas. Frondes monomorfas ou dimorfas; pecíolo com numerosos feixes vasculares arredondados, arranjados em forma de anel na base, sulcado; lâmina simples, 1-pinado-pinatissecta ou 2-pinada; raque adaxialmente sulcada, frequientemente com escamas e/ou tricomas simples ou glandulares na face abaxial; nervuras livres ou anastomosadas. Soros alongados, lineares, formados na face abaxial da lâmina, em ambos os lados da costa, cóstula ou cóstula de $2^{a}$ ordem; indúsio linear, abrindo-se em direção à costa; esporângios longos ou curto-pedicelados, glabros, com ânulo longitudinal e interrompido pelo pedicelo; esporos reniformes, subglobosos, monoletes, aclorofilados, amarelados, perisporo com ornamentação variada.

Os principais caracteres distintivos desta família são a presença de um par de soros lineares paralelo à costa (cenosoro) e indúsio abrindo-se em direção a esta. A família tem distribuição subcosmopolita, sendo reconhecidos nove gêneros (Blechnum L., Brainea J. Sm., Doodia R. Br., Pteridoblechnum Hennipman, Sadleria Kaulfuss, Salpichlaena J. Sm.,
Steenisioblechum Hennipman, Stenochlaena J. Sm. e Woodwardia Sm.) e 250 espécies (Smith 1995, Smith et al.2006). Salpichlaena é um gênero exclusivamente americano (Tryon \& Tryon 1982) e apenas Blechnum e Salpichlaena ocorrem no Brasil.

$\mathrm{Na}$ E.E.P. a família está representada por quatro espécies: Blechnum brasiliense Desv., B. lanceola Sw., B. occidentale L. e B. regnellianum (Kunze) C. Chr.

Blechnum L., Sp. Pl.: 1077. 1753. Tipo: Lectótipo: designado por Smith, Hist. Fil.: 300. 1875: Blechnum occidentale L.

Plantas terrestres, arborescentes a herbáceas, epífitas, hemiepífitas ou rupícolas. Rizoma horizontal ou ereto, às vezes estolonífero, escamoso, escamas peltadas ou basifixas, monocromáticas ou bicolores. Frondes monomorfas ou dimorfas, as férteis geralmente maiores e com pinas mais estreitas; pecíolo e raque geralmente rugosos; lâmina simples, profundamente pinatífita a 1-pinada, raramente 2-pinada, glabra ou com escamas e/ou tricomas aciculares ou glandulares; pinas com margens inteiras ou serreadas, articuladas ou não com a raque; nervuras livres. Soros lineares, paralelos à costa; indúsio linear, abrindo-se em direção à costa, margens inteiras ou erodidas, esporângios pedicelados; esporos subglobosos, monoletes, perisporo alado, rugoso, papiloso ou liso.

O gênero tem distribuição pantropical, com cerca de 200 espécies (Smith 1995, Smith et al. 2006), a maioria ocorrendo no Hemisfério Sul (Proctor 1989). Suas espécies são comuns no interior de florestas úmidas, sombreadas e montanhosas, e também em ambientes com solos encharcados como manguezais, veredas, margens de rios ou, em menor frequiência, sobre rochas ou de hábito epífita (Tryon \& Tryon 1982).

Chave para as espécies de Blechnum da Estação Ecológica do Panga

1. Lâmina inteira, papirácea .................. B. lanceola

1. Lâmina pinatífida a 1-pinada, cartácea a subcoriácea

2. Frondes dimorfas, lâmina 1-pinada, pinas livres e pecioluladas... B. regnellianum

2. Frondes monomorfas, lâmina pinatífida a 1-pinada, pinas adnadas, sésseis

3. Caule ereto com escamas negras a castanho-escuras.... B. brasiliense

3. Caule horizontal com escamas castanho-claras B. occidentale 
Blechnum brasiliense Desv., Ges. Naturf. Freunde Berlin Mag. Neuesten Entdeck. Gesammmten Naturk. 5: 330. 1811. Tipo: BRASIL, Dombey s.n. (holótipo P, Herb. Jussieu 1390, n.v.).

Figura 1A

Plantas terrestres. Caule subarborescente, ca. 3-5 cm diam., ereto, não estolonífero, com escamas ca. 5-20 mm compr., negras a castanhoescuras, monocromáticas ou bicolores, margens inteiras, translúcidas e porção mediana negra, linearlanceoladas, peltadas, ápice acuminado. Frondes (28)72-138 cm compr., monomorfas; pecíolo 0,2-0,7 $\times$ (7-)10-22 cm, escamas semelhantes às do rizoma; lâmina 15-41 × (11-)62-112 cm, elíptica, pinatífida a 1-pinada na porção proximal, glabrescente com tricomas aciculares adpressos a esparsamente pilosas com tricomas glandulares capitados, ca. $0,1 \mathrm{~mm}$ compr., atenuada gradualmente na base, subcoriácea; raque castanho-clara, glabra adaxialmente e glabrescente abaxialmente com tricomas aciculares adpressos, esbranquiçados, 0,5-1 $\mathrm{mm}$ compr., e/ou tricomas glandulares captados, 0,1-0,4 mm compr.; costa glabra adaxialmente, glabrescente abaxialmente com tricomas glandulares capitados semelhantes aos da raque; pinas proximais auriculiformes; pinas medianas (1,1-)1,4-2,0 × (8-)17-21 cm, linearlanceoladas, base truncada, adnadas, tecido laminar entre as nervuras glabro ou com tricomas aciculares e esbranquiçados, ca. 0,1 mm compr., margem serreada, ápice acuminado, pinatífido-pinatissecto; nervuras livres, simples a 1-2 furcadas. Soros lineares, indúsio linear, margem inteira.

Material examinado: BRASIL. Minas Gerais: Uberlândia, Estação Ecológica do Panga, III-1987, M.A. Ranal 416 (HUFU); VII-1987, M.A. Ranal 479 (HUFU), M.A. Ranal 509 (HUFU); VII-1991, M.A. Ranal 548 (HUFU); IV-1992, M.A. Ranal 562 (HUFU); XII-1997, M.A. Ranal 637 (HUFU); VI-1999, M.A. Ranal 744 (HUFU), M.A. Ranal 745 (HUFU), M.A. Ranal 749 (HUFU); VII-1999, M.A. Ranal 789 (HUFU); IX-1999, M.A. Ranal 845 (HUFU); X-1999, M.A. Ranal 867 (HUFU), M.A. Ranal 887 (HUFU), M.A. Ranal 897 (HUFU), M.A. Ranal 906 (HUFU); XI- 1999, M.A. Ranal 923 (HUFU), M.A. Ranal 943 (HUFU), M.A. Ranal 944 (HUFU), M.A. Ranal 965 (HUFU), M.A. Ranal 967 (HUFU), M.A. Ranal 970 (HUFU), M.A. Ranal 971 (HUFU), M.A. Ranal 973 (HUFU), M.A. Ranal 979 (HUFU), M.A. Ranal 980 (HUFU); I-2000, M.A. Ranal 994 (HUFU), M.A.
Ranal 996 (HUFU), M.A. Ranal 1006 (HUFU), M.A. Ranal 1007 (HUFU), M.A. Ranal 1008 (HUFU); II2000, M.A. Ranal 1026 (HUFU); IV-2000, M.A. Ranal 1029 (HUFU); IX-2004, A.A. Arantes \& M.A. Ranal 1288 (HUFU); X-2004, A.A. Arantes \& M.A. Ranal 1350 (HUFU).

Blechnum brasiliense pode ser encontrado na Guatemala, Colômbia, Venezuela, Equador, Peru, Bolívia, Brasil, Paraguai, Argentina e Uruguai (Smith 1995). No Brasil,é amplamente distribuída ocorrendo nas Regiões Nordeste, Centro-Oeste, Sudeste e Sul.

Esta espécie se distingue pelo hábito subarborescente, caule com escamas linear-lanceoladas e negras, que chegam até a base do pecíolo, frondes grandes (72-138 cm compr.) e lâmina atenuada na base, pinatífida e com tricomas adpressos.

A forma encontrada na E.E.P. difere da forma típica pela presença de tricomas glandulares capitados adaxialmente sobre a raque e costa. Esta característica foi observada principalmente em plantas jovens do banco de esporos estudado por Ranal $(2003,2004)$. Os materiais coletados na natureza apresentam frondes glabrescentes, com tricomas adpressos esbranquiçados e tricomas glandulares captados, distribuídos espaçadamente sobre a raque.

$\mathrm{Na}$ área de estudo, Blechnum brasiliense ocorre em locais com solos úmidos, como em barrancos às margens do Ribeirão do Panga e no interior de matas de galeria e veredas.

Blechnum lanceola Sw., Kongl. Vetensk. Acad. Handl. 1817: 71, tab. 3, fig. 2. Tipo: BRASIL, Vila Rica, Freyreis s.n. (holótipo S, n.v.).

Figura 1B-C

Plantas terrestres. Caule 0,4-0,6 cm diâm., ereto, curto, não estolonífero, com poucas escamas, ca. 1-4 mm compr., lanceoladas ou oval-lanceoladas, castanho-claras, margem inteira, ápice acuminado. Frondes 15,0-25,5 cm compr., monomorfas; pecíolo longo, 2-12 cm compr., verde-pálido, com escamas semelhantes às do rizoma; lâmina 1,4-2,1 × 9-13 cm, lanceolada ou elíptica, inteira ou raramente 1-2-lobada na base, glabra, papirácea, base cuneada, ápice agudo, margem inteira; raque castanho-clara, glabra, não sulcada adaxialmente; nervuras livres, simples ou 1-2 furcadas. Soros lineares; indúsio linear, margem inteira.

Material examinado: BRASIL. Minas Gerais: Uberlândia, Estação Ecológica do Panga, III-1999, 

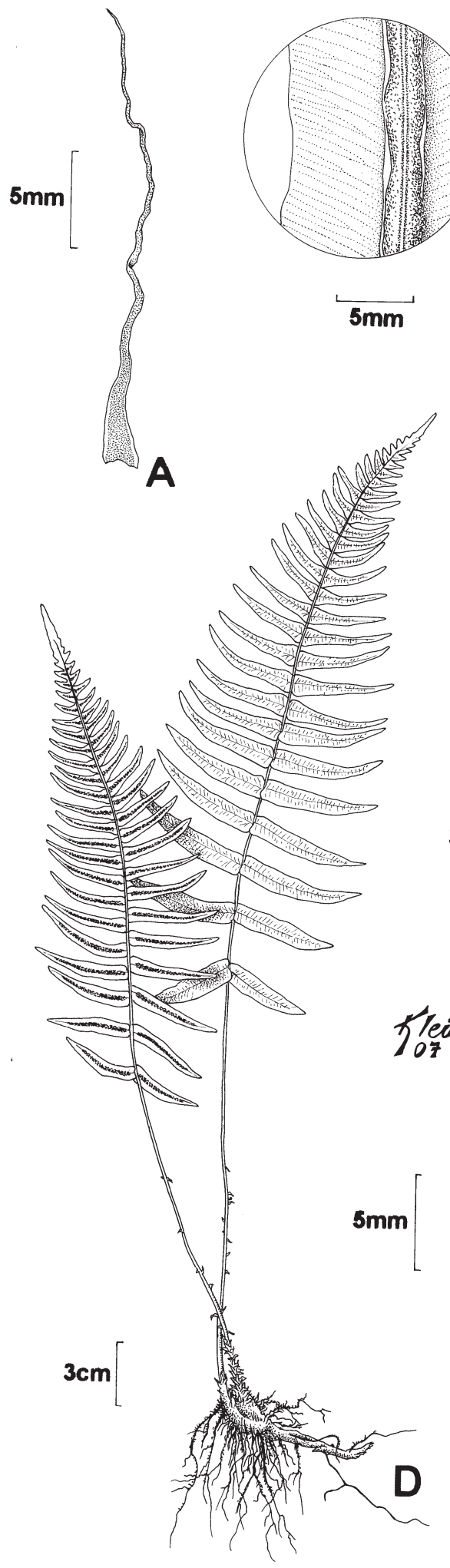


Tlei
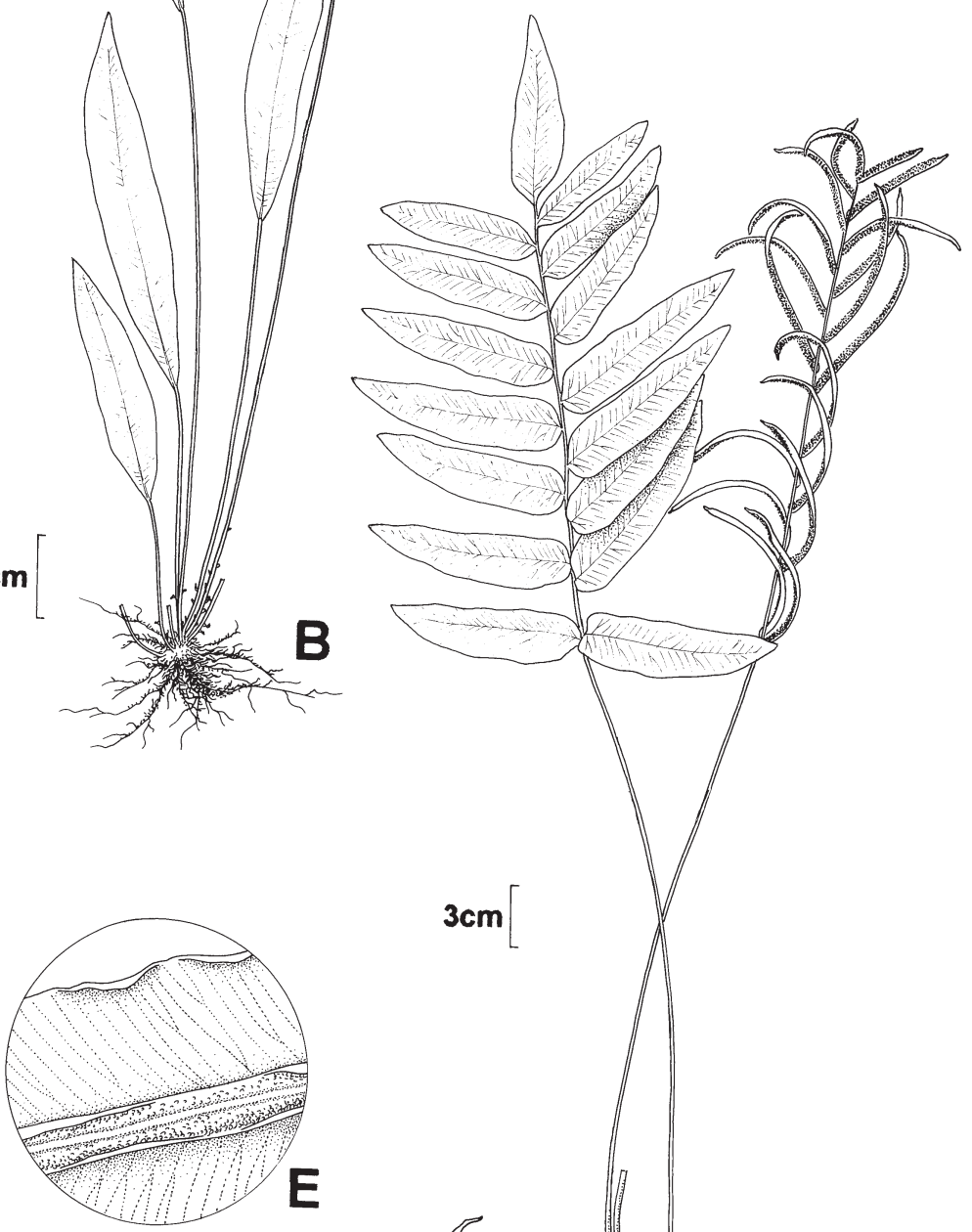

Figura 1. Espécies de Blechnum da Estação Ecológica do Panga, Uberlândia, Minas Gerais. A. Blechnum brasiliense (Ranal 479). A. Escama do pecíolo. B-C. Blechnum lanceola. (Prado \& Ranal 1010). B. Hábito. C. Face abaxial da lâmina, detalhe do soro e indúsio lineares. D-E. Blechnum occidentale (Ranal 486) D. Hábito. E. Face abaxial de uma pina, detalhe do soro e indúsio lineares. F-H. Blechnum regnellianum (Arantes \& Ranal 1299). F. Hábito. G. Escama do pecíolo. H. Face adaxial de uma pina, detalhe das nervuras. 
J. Prado \& M.A. Ranal 1010 (HUFU, SP); XI-1999, A.A. Arantes 1038 (HUFU, HRCB).

Faltam dados sobre a distribuição desta espécie, ela parece possuir distribuição restrita ao Peru, sul da Argentina, Sudeste, Sul e Centro-Oeste do Brasil, sendo coletada nos Estados de Goiás, Minas Gerais, São Paulo e Paraná (com base em material examinado e depositado no herbário SP). Na E.E.P. foi coletada em mata de galeria.

Blechnum lanceola se distingue por apresentar porte pequeno (máximo de $25 \mathrm{~cm}$ compr.) e lâmina simples. $\mathrm{Na}$ área de estudo não foram encontrados espécimes com lâmina lobada na base, conforme a literatura indica (Tryon \& Stolze 1993).

Blechnum occidentale L., Sp. Pl.: 1077. 1753. Lectótipo: designado por Proctor, Ferns Jam.: 289. 1985: Petiver, Pter. Amer. tab. 3, fig. 9. 1712.

Figura 1D-E

Plantas terrestres. Caule 0,8-1,7 cm compr., horizontal, estolonífero, com escamas, 4-9 mm compr., lanceoladas, castanho-claras, basifixas, margem inteira, ápice acuminado. Frondes 10-51 cm compr., monomorfas; pecíolo 0,1-0,4 × 4-20 cm, com escamas semelhantes às do rizoma; lâmina 15-30 cm compr., lanceolada a deltóide, 1-pinada na base, pinatissecta a pinatífida no ápice, glabra, cartácea a subcoriácea; raque castanho-clara, com tricomas aciculares na face abaxial, sulcada adaxialmente, sulcos contínuos com a costa; pinas 0,7-1,9 × 1,9-6 $\mathrm{cm}$, sésseis, lanceoladas a deltóides, base adnada com o lado acroscópico auriculado, ápice obtuso, margem inteira a denticulada; pinas proximais semelhantes às medianas, não reduzidas a levemente reduzidas; nervuras livres, simples a 1-3 furcadas. Soros lineares; indúsio linear, de margem inteira a levemente erodida.

Material examinado: BRASIL. Minas Gerais: Uberlândia, Estação Ecológica do Panga, VIII-1986, M.A. Ranal 388 (HUFU); III-1987, M.A. Ranal 410 (HUFU), M.A. Ranal 426 (HUFU); VII-1987, M.A. Ranal 479 (HUFU); X-1987, M.A. Ranal 486 (HUFU); II-1990, M.A. Ranal 543 (HUFU, HRCB); VII-1991, M.A. Ranal 547 (HUFU), M.A. Ranal 552 (HUFU); IV-1992, M.A. Ranal 568 (HUFU); V-1992, M.A. Ranal 582 (HUFU); VI-1992, M.A. Ranal 598 (HUFU); II-1998, M.A. Ranal 609 (HUFU, SP); XI1999, M.A. Ranal 942 (HUFU); IX-2004, A.A.Arantes \& M.A. Ranal 1246 (HUFU), A.A. Arantes \& M.A.
Ranal 1260 (HUFU); X-2004, A.A. Arantes \& M.A. Ranal 1316 (HUFU), A.A.Arantes \& M.A.Ranal 1326 (HUFU), A.A. Arantes \& M.A. Ranal 1330 (HUFU), A.A. Arantes \& M.A. Ranal 1345 (HUFU), A.A. Arantes \& M.A. Ranal 1346 (HUFU), A.A. Arantes \& M.A. Ranal 1347 (HUFU); XI-2004, A.A. Arantes \& M.A. Ranal 1365 (HUFU).

Esta espécie possui distribuição ampla na região Neotropical ocorrendo desde a Florida (E.U.A.) até o nordeste da Argentina (Smith 1995). No Brasil, ela ocorre nas Regiões Nordeste, Centro-Oeste, Sudeste e Sul (Sehnem 1968), sempre no interior de matas, associada aos ambientes úmidos e aos cursos d água, em elevações entre o nível do mar até $2.000 \mathrm{~m}$ de altitude (Moran 1995).

Na E.E.P.é comum encontrar grandes populações desta espécie, principalmente em bordas de mata de galeria, mata seca e cerradão ou em locais de transição entre essas fitofisionomias.

Blechnum occidentale difere das demais espécies de Blechnum da área pelo caule estolonífero, lâmina lanceolada a deltóide, 1-pinada na base e pinatífida no ápice e pinas sésseis, lanceoladas a deltóides de base truncada e com o lado acroscópico auriculado, dando um aspecto falcado às pinas.

Blechnum regnellianum (Kunze) C. Chr., Ind. fil. Suppl. 1906-1912: 17.1913 झLomaria regnelliana Kunze, Linn 22. 576. 1849. Síntipos: BRASIL. Minas Gerais: "Ad Caldas", Regnell I. 490 (B!, foto); Rio das Contas, Martius s.n. (P?, n.v.).

Figura 1F-H

Plantas terrestres. Caule 1,5-2,3 cm, ereto, não estolonífero, com escamas, 5-19 mm compr., lanceoladas, castanho-claras, basifixas, margem inteira, ápice acuminado. Frondes 47-82 cm compr., dimorfas, eretas, as férteis mais longas e com pinas estreitas e de ápice agudo; pecíolo 0,2-0,6 × 19-30 $\mathrm{cm}$, sulcado abaxialmente, com escamas semelhantes às do rizoma, verrugoso na base, castanho-claro a castanho-avermelhado ou com manchas transversais avermelhadas; lâmina 17-42 × 10,5-22 cm, oblonga, 1-pinada, base truncada ou arredondada, ápice pinatífido, cartácea a subcoriácea; raque castanhoclara a avermelhada, abaxialmente glabra e com escamas lineares na face adaxial (frondes férteis e estéreis), sulcada adaxialmente; pinas 5,5-11,5 cm compr., glabras adaxialmente, abaxialmente com escamas lineares sobre a costa e tricomas simples e curtos sobre as nervuras, pecioluladas a curto- 
pecioluladas, lanceoladas a elípticas, distantes entre si, base livre, arredondada a obtusa, ápice agudo, margens inteiras a denticuladas, revolutas, sem pinas reduzidas; nervuras livres, simples a 1-2-furcadas. Soros lineares, cobrindo quase que inteiramente, exceto a base e ápice da superfície abaxial das pinas férteis, ápice das pinas férteis agudo; indúsio linear, margem erodida.

Material examinado: BRASIL. Minas Gerais: Uberlândia, Estação Ecológica do Panga, XI-1986, M.A.Ranal 393 (HUFU, SP); II-1988, M.A. Ranal 507 (HUFU); VII-1991, M.A. Ranal 551 (HUFU, SP); IV1992, M.A. Ranal 563 (HUFU); V-1992, M.A. Ranal 589 (HUFU); X-2004, A.A. Arantes \& M.A. Ranal 1292 (HUFU, SP), A.A. Arantes \& M.A. Ranal 1296 (HUFU), A.A. Arantes \& M.A. Ranal 1299 (HUFU), A.A. Arantes \& M.A. Ranal 1319 (HUFU).

Esta espécie apresenta ocorrência restrita ao Brasil, com registros para as Regiões Sudeste e Sul (Sehnem 1968). Ela ocorre em ambientes úmidos, margens de cursos d'água e matas de galeria do sudeste e Brasil austral.

Distingue-se das outras espécies da E.E.P. por suas frondes dimorfas, pinas curto-pecioluladas, dispostas alternadamente sobre a raque e o ápice pinatífido da lâmina.

Blechnum regnellianum é muito semelhante a $B$. cordatum (Desv.) Hieron., sendo difícil a distinção baseando-se apenas nas suas descrições originais. Embora os tipos de ambas as espécies não tenham sido examinados, optou-se por adotar neste trabalho o binômio $B$. regnellianum por ser o nome aplicado originalmente ao material brasileiro. Além disto, $B$. cordatum é muito variável e provavelmente compreende um complexo de espécies, sendo necessário um estudo detalhado para melhor compreensão dos seus processos de irradiação (Kessler et al. 2007).

Dentre as espécies do gênero encontradas na área, Blechnum occidentale se assemelha a B. regnellianum, da qual se diferencia pela lâmina de ápice pinatífido, pinas glabras e de base adnada contra, lâmina de ápice conforme, pinas com escamas lineares e tricomas simples na face abaxial e de base livre, características estas presentes em B. regnellianum.

\section{Agradecimentos}

Ao $\mathrm{CNPq}$, pelo apoio financeiro na forma de bolsa de Pós-doutorado Júnior concedida à primeira autora.

\section{Literatura citada}

Arantes, A.A.,Prado, J. \& Ranal,M.A. 2008. Thelypteris subg. Amauropelta (Thelypteridaceae) da Estação Ecológica do Panga, Uberlândia, Minas Gerais, Brasil. Rodriguésia 59: 201-208.

Arantes, A.A., Prado, J. \& Ranal, M.A. 2007a. Macrothelypteris e Thelypteris subg. Cyclosorus (Thelypteridaceae) da Estação Ecológica do Panga, Uberlândia, Minas Gerais, Brasil. Revista Brasileira de Botânica 30: 411-420.

Arantes,A.A., Ranal, M.A.\& Prado,J.2007b. Thelypteris subg. Goniopteris e Meniscium (Thelypteridaceae) da Estação Ecológica do Panga, Uberlândia, Minas Gerais, Brasil. Hoehnea 34: 121-129.

Araújo, G.M., Barbosa, A.A.A., Arantes, A.A. \& Amaral, A.F. 2002. Composição florística de veredas no Município de Uberlândia, MG. Revista Brasileira de Botânica 25: 475-493.

Drummond, G.M., Martins, C.S., Machado, A.B.M., Sebaio,F.A.\& Antonini,Y.(orgs.). 2005. Biodiversidade em Minas Gerais: um atlas para sua conservação. 2 ed. Fundação Biodiversitas, Belo Horizonte.

Kessler, M., Smith, A.R. \& Lehnert, M. 2007. Ten new species and two new combinations of Blechnum (Blechnaceae, Pteridophyta) from Bolivia. American Fern Journal 97: 66-80.

Lellinger, D.B. 2002. A modern multilingual glossary for taxonomic pteridology 3. American Fern Society, Washington, D.C.

Mendonça, R.C., Felfili, J.M., Walter, B.M.T., Silva Júnior, M.C., Rezende, A.V., Filgueiras, T.S. \& Nogueira, P.E. 1998. Flora Vascular do Cerrado. In: S.M. Sano \& S.P. Almeida (eds). Cerrado: Ambiente e Flora. Embrapa - CPAC, Planaltina, pp. 289-556.

Moran, R.C. 1995. Blechnaceae. In: R.C. Moran \& R. Ribas (eds.). Psilotaceae a Salviniaceae. In: G. Davidse, M. Souza \& S. Knapp (eds.). Flora Mesoamericana. Universidad Nacional Autónoma de México, Ciudad de México, v. 1, pp. 325-333.

Pichi-Sermolli, R.E.G. 1996. Authors of scientific names in Pteridophyta. Royal Botanic Gardens, Kew.

Prado, J. 1992. Flora da Serra do Cipó, Minas Gerais: Pteridaceae-Cheilanthoideae. Boletim de Botânica da Universidade de São Paulo 13: 141-159.

Prado, J. 1997. Flora da Serra do Cipó, Minas Gerais: Pteridaceae-Adiantoideae e Taenitidoideae. Boletim de Botânica da Universidade de São Paulo 16: 115-118.

Proctor, G.R. 1989. Ferns of Puerto Rico and the Virgin Islands. Memoirs of the New York Botanical Garden 53: 1-389.

Ranal, M.A. 2003. Soil spore bank of ferns in a gallery forest of the Ecological Station of Panga, Uberlândia, MG, Brazil. American Fern Journal 93: 97-115. 
Ranal, M.A. 2004. Bark spore bank of ferns in a gallery forest of the Ecological Station of Panga, Uberlândia, MG, Brazil. American Fern Journal 94: 57-69.

Ribeiro, J.F. \& Walter, B.M.T. 1998. Fitofisionomias do bioma cerrado. In: S.M. Sano \& S.P. Almeida (eds). Cerrado: ambiente e flora. EMBRAPA - CPAC, Planaltina, pp. 89-168.

Sehnem, A. 1968. Blecnáceas. In: R. Reitz (ed.). Flora Ilustrada Catarinense. Herbário Barbosa Rodrigues, Itajaí, pp.1-90.

Smith, A.R. 1995. Blechnaceae. In: P.E Berry, B.K. Holst \& K. Yatskievych (eds.). Flora Pteridophytes, Spermatophytes: Acanthaceae-Araceae. In: J.A.
Steyermark, P.E. Berry \& B.K. Holst (eds.). Flora of the Venezuelan Guayana. Missouri Botanical Garden \& Timber Press, Saint Louis. v. 2, pp: 23-29.

Smith, A.R., Pryer, K.M., Schuettpelz, E., Korall, P., Schneider, H. \& Wolf, P.G. 2006. A classification for extant ferns. Taxon 55: 705-731.

Tryon, R.M. \& Stolze, R.G. 1993. Pteridophyta of Peru. Part. V. - 18. Aspleniaceae - 21. Polypodiaceae. Fieldiana, Botany, new series 32: 1-190.

Tryon, R.M. \& Tryon,A.F. 1982. Ferns and allied plants, with special reference to Tropical America. SpringerVerlag, New York. 